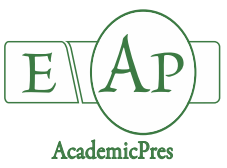

Tran QT et al. (2020)

Notulae Botanicae Horti Agrobotanici Cluj-Napoca 48(2):826-838

DOI: $10.15835 /$ nbha 48211884

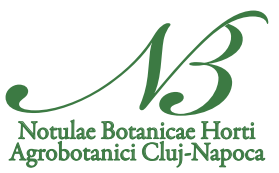

\title{
Biological activities of in vitro liverwort Marchantia polymorpha L. extracts
}

\author{
Tan Q. TRAN ${ }^{1}$, Hoang N. PHAN ${ }^{2}$, Anh L. BUI ${ }^{3}$, \\ Phuong N. D. QUACH ${ }^{3 *}$ \\ ${ }^{1}$ University of Science, Vietnam National University, Faculty of Biology - Biotechnology, Molecular Biotechnology Laboratory, Ho Chi \\ MinhCity,Vietnam; tqtan@hcmus.edu.vn \\ ${ }^{2}$ University of Science, Vietnam National University, Faculty of Biology - Biotechnology, Department of Plant Physiology, Ho Chi Minh \\ City,Vietnam;pnhoang@bcmus.edu.vn \\ ${ }^{3}$ University of Science, Vietnam National University, Faculty of Biology - Biotechnology, Department of Plant Biotech and \\ Biotransformation, Ho Chi Minh City,Vietnam; blanh@hcmus.edu.vn; qndphuong@hcmus.edu.vn (*corresponding author)
}

\begin{abstract}
To overcome the problems in liverwort collecting such as small size and easily mixed with other species in the wild, we have successfully cultivated Marchantia polymorpha L. under in vitro conditions in the previous study. The aim of this study is to evaluate the biological activities of this in vitro biomass as a confirmation of the sufficient protocol in cultivation this species. Cultured biomass was dried at a temperature of $45-50{ }^{\circ} \mathrm{C}$ to constant weight and ground into a fine powder. The coarse powder was extracted with organic solvents of increasing polarization including $\mathrm{n}$-hexane, chloroform, ethyl acetate, and ethanol using the maceration technique. Four extracts were investigated antioxidant (iron reduction power, DPPH), antibacterial (agar diffusion), tyrosinase inhibitory activity, anti-proliferation on MCF-7 cells. Additionally, the presence of natural metabolite groups of the extracts was detected by using specific reagents. For antioxidant activity, ethyl acetate fraction extract had the highest iron reducing power and DPPH free radical scavenging ability with IC50 $=439.31 \mu \mathrm{g} \mathrm{ml}^{-1}$. All three $\mathrm{n}$-hexane, chloroform, and ethyl acetate extracts possessed resistance to the bacterial strain tested. At a concentration of $2 \mathrm{mg} \mathrm{ml}^{-1}$, $\mathrm{n}$-hexane and chloroform extracts had the highest percentage of tyrosinase inhibition (69.54 and 69.10\%, respectively). The n-hexane extract is a potent extract that inhibits the proliferation of MCF-7 cells with the lowest $\mathrm{IC}_{50}$ of $38.15 \mu \mathrm{g} \mathrm{m}{ }^{-1}$. A preliminary chemical composition survey showed that the cultured biomass liverwort contains many bioactive compounds, particularly the compounds of range of non- and less-polarized fractions.
\end{abstract}

Keywords: biological activities; in vitro biomass; liverwort; Marchantia polymorpha L.

\section{Introduction}

Marchantia polymorpha L. is a common liverwort species, widely distributed in many parts of the world (Asakawa et al., 2000; Shimamura, 2015). Their habitat may range from humid tropical rain forests to dense urban areas (Shimamura, 2015). Currently, this non-vascular plant species is manipulated as a model plant in 
molecular biology experiments related to the adaptation of terrestrial plants (Bowmann et al., 2007). Because this plant can maintain under laboratory conditions, in addition, the single haploid chromosome makes molecular biology approaches easier to perform, and the phenotypic results are easy to evaluate because several genotypes control the phenotype (Tanaka et al., 2016).

In terms of medicine and pharmaceutical, Marchantia polymorpha has long been used as the folk medicinal experience of some countries such as China and India to help diuretic activity, hepatitis, open wounds and burns, insects, and snake bites, etc (Asakawa et al., 2013; Chandra et al., 2016). Studies on liverworts and Marchantia polymorpha as a member show that these plants a fascinating group because they can produce a wide range of bioactive compounds (Asakawa and Ludwiczuk, 2013; Asakawa et al., 2013). Besides, the small, fragile body structure and the absence of a vascular system require the effectiveness of these compounds to help these plants adapt to attack from outside agents and survive under challenging conditions (Asakawa et al., 2013). The secondary metabolites found in Marchantia polymorpha are volatile compounds that belong to the terpenoids (for example, thujopsene, $\beta$-chamigrene, etc.) and aromatic compounds, including bibenzyls and bisbibenzyls (Asakawa et al., 2013; Tanaka et al., 2016). Biological activity investigations show the potential of some bisbibenzyl structures such as marchantin $\mathrm{A}, \mathrm{C}$, perrottetin $\mathrm{E}$, etc., to exhibit many activities including antibacterial, antifungal, antiviral, anti-inflammatory, anti-proliferation of cancer cell lines, etc (Asakawa et al., 2000; Asakawa et al., 2013).

The most significant difficulty when approaching this group of plants in the process of studying natural compounds and biological activity is biomass (Asakawa et al., 2013; Hans et al., 1991). Bryophytes collection in the natural habitats endures many obstacles because these species are small in size, fragile, and mixed between many species, causing the biomass impure (Hans et al., 1991). For instance, Southeast Asia regions, with its humid climate, is a suitable place for many types of liverworts to grow, resulting in the collection of samples often mixed with many different species of leafy liverworts family-Lejeuneaceae (Asakawa and Ludwiczuk, 2017). Therefore, axenic culture can be considered as an independent and proactive method of biomass collection to overcome the problems mentioned above (Hans et al., 1991).

In Vietnam, we also noted the presence of Marchantia polymorpha, but there have been limited published claims regarding the use of this liverwort in treating some folk diseases or the natural compounds (Asakawa et al., 2000). Along with the difficulties in the sample collection, we have successfully researched and cultivated this species under in vitro conditions in order to collect pure materials proactively (Tan et al., 2020). This source should be estimated for biological activities and secondary metabolites. Because several studies around the world have shown that in vitro cultivating bryophytes are more active with wild-type specimens, as concluded by Aneta et al. when studying the antifungal activity of some mosses such as Atrichum undulatum, Physcomitrella patens (Aneta et al., 2011). Or the study of Sabovljevic and colleagues on Marchantia polymorpha subsp. ruderalis found that in vitro culture materials could produce new bisbibenzyls which are not available in a natural source (Sabovljevic et al., 2016).

In this study, the in vitro biomass was evaluated through investigations of some biological activities, thereby providing reference information for this liverwort species in Vietnam, which is not fully documented for both folk experience and scientific evidence.

\section{Materials and Methods}

\section{Materials}

Liverwort Marchantia polymorpha L. was obtained from the improved culture process of Tan et al. (2020), in which, the liverwort was cultured on liquid half-strength Gamborg B5 medium, supplemented with $20 \mathrm{~g} \mathrm{l}^{-1}$ sucrose, $1.5 \mathrm{~g} \mathrm{l}^{-1}$ tryptone, $\mathrm{pH}$ adjusted to 5.5-5.6, illuminated by blue LED light ( $455 \mathrm{~nm}$ ) and light 
intensity of 2300 lux, culture substrate is a cotton swab layer. The cultivate medium was autoclaved in 20 minutes, 1 atm and $121{ }^{\circ} \mathrm{C}$. After 7 weeks of culture, the liverwort biomass was harvested, washed under running tap water and dried at a temperature of $50^{\circ} \mathrm{C}$.

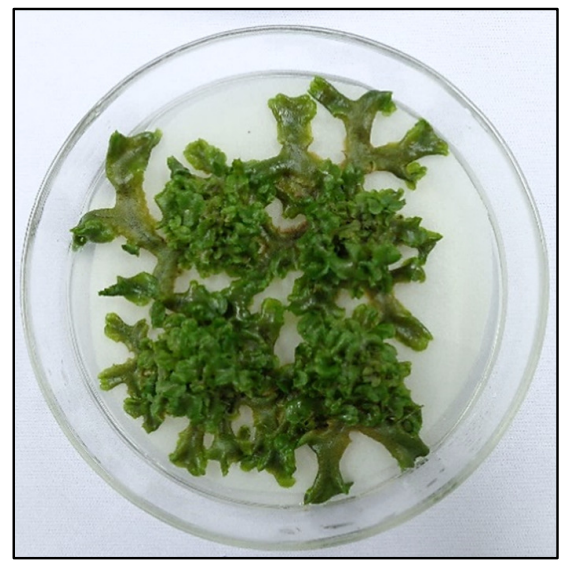

Figure 1. Marchantia polymorpha L. in improved cultured process (bar: $1 \mathrm{~cm}$ )

Bacterium strains including Gram-positive (Enterococcus faecalis ATCC 29212, Staphylococcus aureus ATCC 25923, Staphylococcus epidermidis ATCC 12228) and Gram-negative (Vibrioparahaemolyticus ATCC 17802, Salmonella typhimurium ATCC 14028, Pseudomonas aeruginosa ATCC 27853) was stored and provided by Department of Plant Biotechnology and Biotransformation, Faculty of Biology and Biotechnology, University of Science, VNU-HCMC, Viet Nam. The Luria-Bertani Broth (LB) medium (yeast extract $5 \mathrm{~g} \mathrm{l}^{-1}$, tryptone $10 \mathrm{~g} \mathrm{l}^{-1}, \mathrm{NaCl} 10 \mathrm{~g} \mathrm{l}^{-1}$ ) was used to grow bacteria supplemented with $15 \mathrm{~g} \mathrm{l}^{-1}$ agar and adjusted $\mathrm{pH}$ to 7.0 , autoclaved in $20 \mathrm{~min}, 1$ atm and $121^{\circ} \mathrm{C}$.

\section{Preparation of fraction extracts}

After drying at $50{ }^{\circ} \mathrm{C}$ to constant mass, the liverwort sample was ground into a powder. This powder was used to prepared fraction extracts based on maceration method reference from Nada $e t$ al., (2016). First, the powder was soaked with $\mathrm{n}$-hexane at the ratio of $1 \mathrm{~g}$ powder: $10 \mathrm{ml}$ solvent, the mixture was filtered, and the extract was collected using a vacuum rotary evaporator (HS-2005S-N, Hahnshin Scientific Co.). This process was carried out repeatedly until exhaustion. Plant powder after being extracted with $n$-hexane will be replaced successively with the other solvents of increasing polarization, including chloroform, then ethyl acetate and ethanol as final.

\section{Evaluating reducing power}

Liverwort extracts were evaluated for their reduction capacity through participation in the conversion of $\mathrm{Fe}^{3+} / \mathrm{K}^{3}\left[\mathrm{Fe}(\mathrm{CN})^{6}\right]$ to $\mathrm{Fe}^{2+} / \mathrm{K}^{4}\left[\mathrm{Fe}(\mathrm{CN})^{6}\right]$ as reported by Manmohan et al. (2014) with some minor modifications. Firstly, $1 \mathrm{ml}$ of the extract (2 mg.ml-1 in ethanol or DMSO) in a test tube is mixed with $2.5 \mathrm{ml}$ of sodium phosphate buffer $(0.2 \mathrm{M}$ and $\mathrm{pH} 6.6)$ and $2.5 \mathrm{ml}$ of $1 \% \mathrm{~K}_{3}\left[\mathrm{Fe}(\mathrm{CN})_{6}\right]$. The mixture is incubated at $50{ }^{\circ} \mathrm{C}$ for $20 \mathrm{~min}$. Continue adding $2.5 \mathrm{ml}$ of $1 \%$ trichloroacetic acid to the mix and chill. Centrifuge the solution at $2000 \mathrm{rpm}$ for $10 \mathrm{~min}$ to remove the precipitate. $1 \mathrm{ml}$ of the supernatant is added with $2 \mathrm{ml}$ of distilled water, $0.5 \mathrm{ml}$ of $1 \% \mathrm{FeCl}_{3}$, and mix. The mixture absorbance is detected at $700 \mathrm{~nm}$ after $5 \mathrm{~min}$.

\section{DPPH scavenging assay}

The fractional extract was dissolved in an ethanol solution containing 10\% DMSO (v/v) and diluted in concentrations gradually reduced from 5 to $0 \mathrm{mg} \mathrm{ml}^{-1} .0 .5 \mathrm{ml}$ of the test extract solution was mixed with $3 \mathrm{ml}$ 
of absolute ethanol. The mixture was then added with an additional $0.5 \mathrm{ml}$ of DPPH $0.6 \mathrm{mM}$ (prepared in absolute ethanol) (Ghasemi et al., 2009). The mixture was shaken well and incubated in the dark for $30 \mathrm{~min}$ at $28-30{ }^{\circ} \mathrm{C}$. The solutions were then measured with a $517 \mathrm{~nm}$ wavelength absorbance. The formula calculated the percentage of free radical scavenging:

$\%$ Inhibition $=1-\frac{\mathrm{At}}{\mathrm{Ac}} \times 100$

In which, At and Ac is the absorbance value of the test sample and the negative control (ethanol containing $10 \%$ DMSO), respectively. Based on the corresponding percentage value of each decreasing concentration, the $\mathrm{IC}_{50}$ value was calculated.

\section{Agar diffusion for anti-bacterial investigation}

Anti-bacterial activity was investigated by agar diffusion method (Balouiri et al., 2016). First, the bacteria are cultured in liquid LB medium to reach OD $625 \mathrm{~nm} \geq 0.5$, then the bacterial solution is adjusted to OD 625 $\mathrm{nm}$ in the range of 0.1 to 0.15 and bring $100 \mu \mathrm{l}$ to spread on Petri dish containing LB agar medium. A $7 \mathrm{~mm}$ diameter aluminum tube is used to make the agar wells, and each well was added $50 \mu \mathrm{l}$ of test solution. The test solutions include a $0.4 \mathrm{mg} \mathrm{ml}^{-1}$ chloramphenicol as positive control, $60 \mathrm{mg} \mathrm{ml}^{-1}$ test extracts and a negative control-aqueous solution containing $10 \%$ DMSO. After incubation of the petri dishes in the dark at $37^{\circ} \mathrm{C}$ for $24 \mathrm{~h}$, the diffusion zones from the agar wells were recorded in diameter and calculated by the formula:

Inhibitory zone $(\mathrm{mm})=$ diameter of the diffusion zone of the test solution $(\mathrm{mm})$ - diameter of the diffusion zone of negative control $(\mathrm{mm})$.

\section{Tyrosinase inhibitory activity assay}

The inhibitory activity of tyrosinase was conducted according to the procedure of Hanh et al., (2017) with some minor modifications. The experiment was conducted with a 96-well plate, each initially containing $70 \mu \mathrm{l}$ of the liverwort extract made in potassium phosphate buffer $(50 \mathrm{mM}$ and $\mathrm{pH} 6.8)$ containing $5 \%$ DMSO, $30 \mu \mathrm{l}$ mushroom tyrosinase solution (Sigma T3824-25KU) $124.61 \mathrm{U} \mathrm{ml}^{-1}$. The mixture was incubated at 32$34^{\circ} \mathrm{C}$ for $15 \mathrm{~min}$. Then, continue to add $110 \mu \mathrm{l}$ of L-tyrosine substrate $2 \mathrm{mM}$ and incubate for another $20 \mathrm{~min}$. The product of the reaction was measured for absorbance at $490 \mathrm{~nm}$. The blank sample is enzyme-free and the negative control is a non-extracts sample. Fraction extracts were prepared at $2 \mathrm{mg} \mathrm{ml}^{-1}$ and positive control was kojic acid at $200 \mu \mathrm{g} \mathrm{ml}^{-1}$.

The percentage of inhibition is calculated by the formula:

$\%$ Inhibition $=1-\frac{(\text { As-Asb) }}{(A c-A c b)} \times 100$

With:

As: mixture absorbance of test sample

Asb: mixture absorbance of test blank sample

Ac: mixture absorbance of negative control

Acb: mixture absorbance of negative blank control

\section{Anti-proliferation of MCF-7 using SRB method}

The experiment was conducted according to the process of My-Nuong and Thuy-Duong, (2016) with some minor modifications. MCF-7 breast cancer cells are grown and spread on a plate of 96 -wells so that each well contains $100 \mu \mathrm{l}$ medium and 10,000 cells. The cells were investigated with extract at a concentration of $100 \mu \mathrm{g} \mathrm{ml}^{-1}$, parallel to the negative control DMSO $0.25 \%$ and positive control-camptothecin $0.05 \mu \mathrm{g} \mathrm{ml}^{-1}$. After 48 hours of induction, the cells were washed and fixed with $50 \%$ cold trichloroacetic acid, continued to stain sulforhodamine B (SRB) $0.2 \%$ for 20 min, washed 4 times with acetic acid $1 \%$, allowed to dry for 12 to 24 hours and dissolve the SRB completely with Tris $10 \mathrm{mM}$ in $10 \mathrm{~min}$. The absorbance value (measured with 
an ELISA reader) was calculated by the $492 \mathrm{~nm}$ wavelength absorbance minus $620 \mathrm{~nm}$ absorbance value. The percentage of cell proliferation inhibition is calculated by the formula:

$\%$ Inhibition $=1-\frac{\mathrm{At}}{\mathrm{Ac}} \times 100$

In which, At and Ac are the absorbance value of the extract sample and negative control, respectively.

\section{Detection of some secondary metabolites by using specific reagents}

The experiment was conducted in consultation with Harborne, (1984) and Jayaveera et al., (2010) to determine the presence of typical secondary metabolites in plant extracts. Metabolite groups (with corresponding reagents) include: phenolics $\left(\mathrm{FeCl}_{3} 5 \%\right)$, quinone and coumarin ( $\mathrm{KOH} \mathrm{5 \% /methanol),} \mathrm{tannins}$ (saline gelatin), alkaloids (Wagner reagent), flavonoids (concentration sulfuric acid, lead acetate $10 \%, \mathrm{NaOH}$ 1\%/ethanol, Cyanidin test), terpenoid (Rosenheim for tri-terpen and Salkowski reaction for steroid, saponin foaming reaction), glycoside derivatives (Molisch reagent) and lactone ring compounds (Baljet reagent). The experiment was carried out simultaneously between liverwort extract samples at $2 \mathrm{mg} \mathrm{m}^{-1}$ and ethanol containing $10 \%$ DMSO as negative control.

\section{Statistical analysis}

Each experiment was repeated three times to obtain results except the preparation phase of liverwort fraction extracts. All data was processed by SPSS 16.0 (IBM SPSS Inc.) and Microsoft Excel 2010 (Microsoft Software). Results were presented as means and standard deviations (Mean \pm SD). The Duncan test is used to evaluate statistical differences at level of $\mathrm{p}<0.05$.

\section{Results and Discussion}

\section{Preparation of fraction extracts}

The extraction efficiency compared to the dry mass $(24.20 \mathrm{~g})$ of the cultured plant sample ( $409.28 \mathrm{~g})$ was recorded in Table 1.

Table 1. Fraction extracts' mass (g) and efficiency (\%) of extracts compared to dried weight ( $24.20 \mathrm{~g})$ of in vitro cultured liverwort Marchantia polymorpha $\mathrm{L}$

\begin{tabular}{|c|c|c|}
\hline Fraction extracts & Extract's mass (g) & Efficiency (\%) \\
\hline n-Hexane & 0.32 & 1.32 \\
\hline Chloroform & 0.43 & 1.78 \\
\hline Ethyl acetate & 0.32 & 1.32 \\
\hline Ethanol & $\mathbf{1 . 2 7}$ & $\mathbf{5 . 2 6}$ \\
\hline
\end{tabular}

The ethanol fraction had the largest mass and extraction efficiency (1.27 g and 5.26\%, respectively), followed by chloroform, the two extracts had the same lowest extraction efficiency of $n$-hexane and ethyl acetate with $1.32 \%$. As can be seen that in vitro cultured biomass of Marchantia polymorpha contained more compounds with strong polarity, better solubility in ethanol than weak and medium polar compounds.

\section{Evaluating reducing power}

The reducing capacity of the test substance is expressed through the $700 \mathrm{~nm}$ wavelength absorbance, the higher the absorbance value, the greater the reduction capacity. Absorbance values of $700 \mathrm{~nm}$ wavelength for positive samples and ascorbic acid are shown in Table 1 . The concentration of ascorbic acid is $0.5 \mathrm{mg} \mathrm{ml}^{-1}$ and the extracts are $2 \mathrm{mg} \mathrm{ml}^{-1}$.

The ethyl acetate extract had the highest absorbance compared to the rest, which means that the reducing power of this extract is the greatest among the four fractions (Figure 2). The remaining extracts had 
reducing capacity in descending order of chloroform, hexane, and finally ethanol. Although different in test concentration, the extracts did not stand out when compared to the positive ascorbic acid (absorbance nearly six times higher than the absorbance of ethyl acetate).

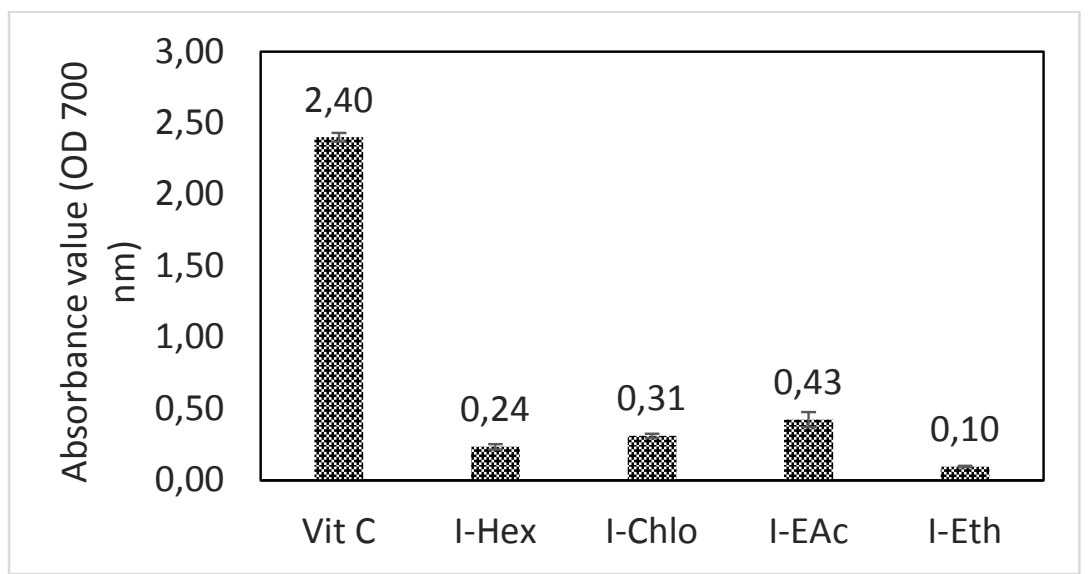

Figure 2. Absorption value at the wavelength of $700 \mathrm{~nm}$ of fractional extract samples and positive vitamin C. Note: Vit C-Ascorbic acid; I-Hex, -Chlo, -EAc and -Eth correspond to n-hexane, chloroform, ethyl acetate, and ethanol extracts

\section{DPPH scavenging activity}

In addition to the reduction capacity, the extracts were also assessed for their ability to scavenge free radicals. In this model, the $\mathrm{IC}_{50}$ (half-maximal inhibition concentration) value will show the DPPH's free radical scavenging capacity of a substance or a test sample, notably the lower the $\mathrm{IC}_{50}$ cost, the stronger the antioxidant capacity is. $\mathrm{IC}_{50}$ values of extracts and ascorbic acid are presented in Table 2.

Ethyl acetate extract had the most excellent ability in free radical scavenging with the lowest $\mathrm{IC}_{50}$ of the four extracts $\left(439.31 \mathrm{~g} \mathrm{~m}^{-1}\right)$. The next is the chloroform fraction $\left(487.14 \mu \mathrm{g} \mathrm{ml}^{-1}\right)$, and the position of the other two extracts is similar to that of the reduction power test. In particular, the $\mathrm{IC}_{50}$ value of ethanol is very high, six times higher than the ethyl acetate extract, which shows the lightest scavenging ability of this fraction.

Table 1. Half-maximal inhibition concentration $\left(\mathrm{IC}_{50}\right)$ values of four extracts and ascorbic acid in DPPH scavenging ability

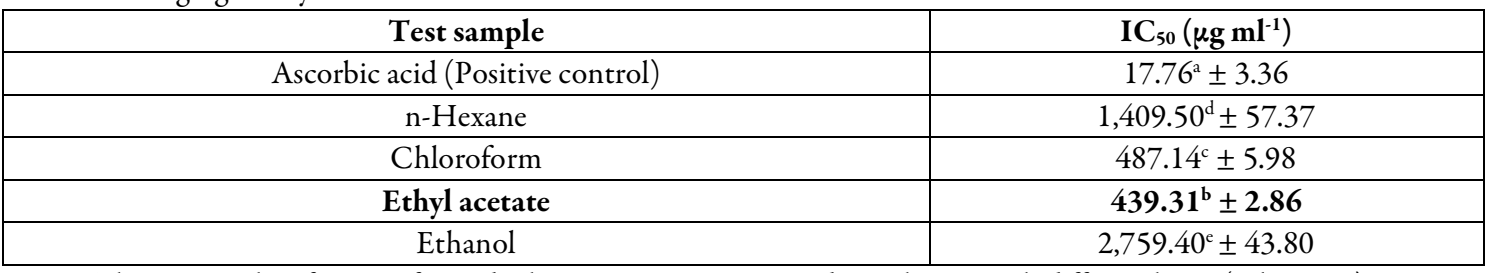

The $\mathrm{IC}_{50}$ results of DPPH free radicals scavenging are compared in columns, each different letter $(\mathrm{a}, \mathrm{b}, \mathrm{c}$, etc.) is corresponding to each mean showing a statistical difference with $\mathrm{p}<0.05$.

The recent $M$. polymorpha L. antioxidant activity evaluation of Gokbulut et al. (2012) on ethyl acetate and methanol extracts showed that ethyl acetate fraction was better than methanol fraction. The similar results are obtained here with better antioxidant activity in ethyl acetate extract than ethanol extract.

Remya and Murugan, when investigating the antioxidant activity of the wild Marchantia polymorpha, reported that this species exhibits antioxidant ability through FRAP (ferric-reducing capacity), neutralizing free radicals' $\mathrm{DPPH}, \mathrm{ABTS}, \mathrm{OH}^{-}$and protect DNA. Moreover, they found that this liverwort contains several compounds 
such as gallate, protocatechol, etc. with coumarins, glycoside derivatives act as reducing agents (Remya and Murugan, 2013).

\section{Anti-bacterial activity by generating inbibited zone}

Antimicrobial activity was assessed through a diameter $(\mathrm{mm})$ of the diffusion zone from the agar well. Results of the width of the antibacterial region of 4 extracts ( $3 \mathrm{mg}$ per well) and chloramphenicol- positive control are presented in Table 3.

Table 2. Diameter of inhibited zones of four extracts and chloramphenicol on six bacterial strains

\begin{tabular}{|c|c|c|c|c|c|}
\hline \multirow{2}{*}{ Bacteria strains } & \multicolumn{5}{|c|}{ Diameter of inhibited zones $(\mathrm{mm})$} \\
\cline { 2 - 6 } & Chloramphenicol & n-Hexane & Chloroform & Ethyl acetate & Ethanol \\
\hline V.parahaemolyticus & $21.00^{\mathrm{a}} \pm 1.00$ & $9.00^{\mathrm{b}} \pm 3.61$ & $10.33^{\mathrm{b}} \pm 2.89$ & $9.00^{\mathrm{b}} \pm 3.46$ & - \\
\hline S. typhimurium & $19.33 \pm 0.58$ & - & - & - & - \\
\hline P. aeruginosa & $11.33^{\mathrm{a}} \pm 0.58$ & - & - & $4.67^{\mathrm{b}} \pm 1.15$ & - \\
\hline E. faecalis & $9.67^{\mathrm{a}} \pm 1.15$ & $4.00^{\mathrm{b}} \pm 1.00$ & $4.67^{\mathrm{b}} \pm 1.15$ & $5.67^{\mathrm{b}} \pm 1.15$ & - \\
\hline S. aureus & $27.67^{\mathrm{a}} \pm 0.58$ & $9.67^{\mathrm{bc}} \pm 3.05$ & $11.33^{\mathrm{b}} \pm 3.21$ & $5.67^{\mathrm{cd}} \pm 2.89$ & - \\
\hline S. epidermidis & $20.67^{\mathrm{a}} \pm 2.52$ & $7.33^{\mathrm{bc}} \pm 1.53$ & $7.00^{\mathrm{bc}} \pm 1.00$ & $5.33^{\mathrm{c}} \pm 0.58$ & - \\
\hline
\end{tabular}

The diameter results are compared in each row, each different letter (a, b, c, etc.) is corresponding to each mean showing a statistical difference with $\mathrm{p}<0.05$. (-): Not detected

Results of inhibited zone diameters showed that all six bacteria strains were sensitive to chloramphenicol with a concentration of $25 \mu \mathrm{g}$ per well, for $P$. aeruginos $a$, the concentration was increased to $500 \mu \mathrm{g}$ per well. For gram-negative strains, three fractions from n-hexane to ethyl acetate all inhibited $V$. parahaemolyticus, while no extracts inhibited $S$. typhimurium. Exceptionally, only ethyl acetate fraction can inhibit $P$. aeruginosa, which is a remarkable record because there are currently very few substances that can hinder this bacterium. For gram-negative strains, three fractions such as $n$-hexane, chloroform, and ethyl acetate all inhibited well with all strains, almost no statistically significant difference concerning the diameter of antibacterial zones in $E$. faecalis. For the two strains of Staphylococcus, the n-hexane and chloroform extracts were slightly higher than the ethyl acetate fraction. At least, the ethanol fraction did not inhibit all bacteria strains examined.

Studies on the natural Marchantia polymorpha samples also noted that extracts from weakly polar solvents such as chloroform had better activity than highly polarized solvents such as ethanol or methanol (Gahtori and Chaturvedi, 2011; Singh et al., 2011). Besides, Gahtori and Chaturvedi's research also showed that the chloroform and methanol extracts of $M$. polymorpha have no inhibitory activity against Salmonella enterica (Gahtori and Chaturvedi, 2011). In present study, in vitro cultured liverwort, chloroform, ethyl acetate, and even $\mathrm{n}$-hexane fraction exhibited more outstanding antibacterial activity than ethanol fraction. Besides, the antimicrobial compounds from Marchantia polymorpha are mainly in the bisbibenzyl group (Asakawa et al., 2013; Tanaka et al., 2016; Asakawa and Ludwiczuk, 2017), which predicts that the cultured material may also produce similar compounds and that they could be distributed into from $\mathrm{n}$-hexane to ethyl acetate.

\section{Tyrosinase inhibitory activity}

The enzyme inhibiting capacity of kojic acid was powerful, at concentrations ten times lower than the extract; the positive control inhibited almost 100\% tyrosinase enzyme activity (Figure 3). In terms of in vitro liverwort extracts, the three $\mathrm{n}$-hexane, chloroform, ethyl acetate extracts still had a much better attribute than the ethanol fraction. Of which, $\mathrm{n}$-hexane and chloroform extracts were the two potential inhibiting extracts with no significant difference in the percentage of inhibition (69.54 and 69.10\%, respectively). Reports on biological activities and metabolites on $M$. polymorpha did not mention much on tyrosinase inhibitory activity 
(Asakawa et al., 2013; Asakawa and Ludwiczuk, 2017). Recently, Gawel-Beben et al. (2019) announced that marchantin A, a weak polar bisbibenzyl group, did not inhibit tyrosinase activity. Meanwhile, these in vitro $M$. polymorpha $\mathrm{n}$-hexane and chloroform extracts may contained other weak polar potential bioactive compounds have not been investigated.

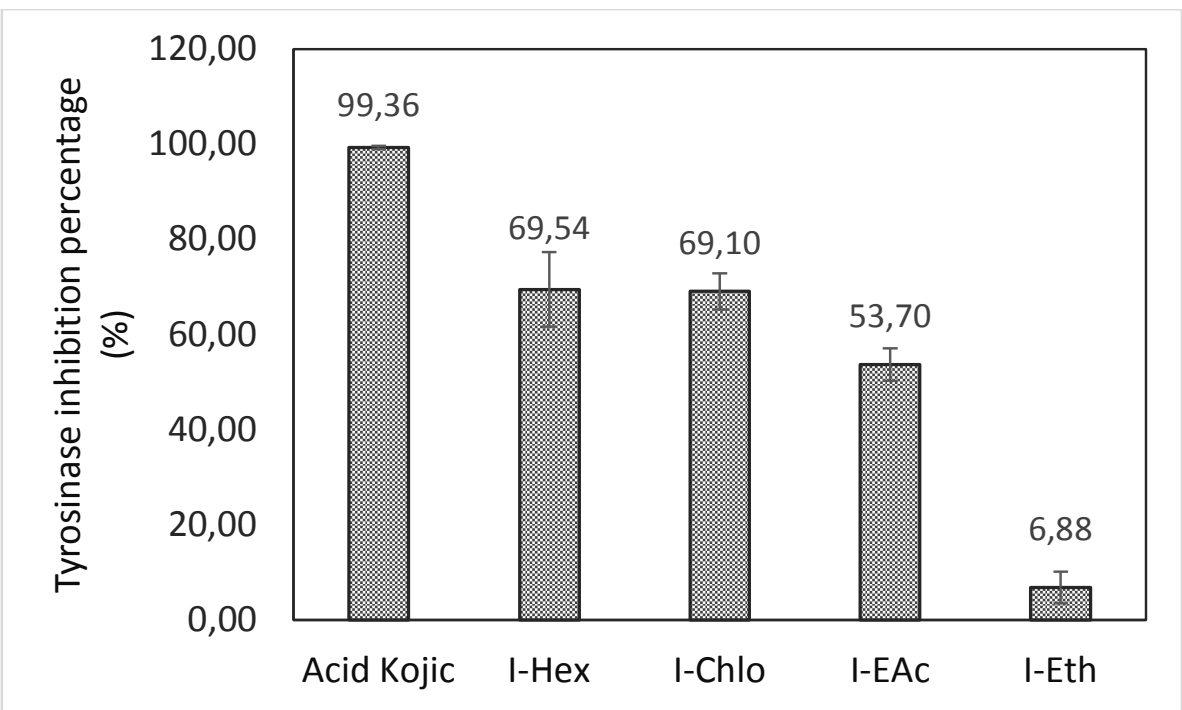

Figure 3. Tyrosinase inhibition percentage (\%) of kojic acid as positive control and four extracts of cultured Marchantia polymorpha

Note: I-Hex, -Chlo, -EAc and -Eth correspond to n-hexane, chloroform, ethyl acetate, and ethanol extracts

\section{Anti-proliferation activity on MCF-7 cell lines}

At a concentration of $100 \mu \mathrm{g} \mathrm{ml}^{-1}$, three extracts of $\mathrm{n}$-hexane, chloroform, ethyl acetate all inhibited the proliferation of MCF-7 cells higher than 60\% (Table 4). Therefore, the $\mathrm{IC}_{50}$ index (a concentration that inhibits $50 \%$ of cell growth) was determined for these three extracts through a gradual reduction of the extract concentration from 100 to $0 \mu \mathrm{g} \mathrm{ml}^{-1}$. The $\mathrm{n}$-hexane extract has the lowest $\mathrm{IC}_{50}$ value, which means that this extract inhibits the proliferation of MCF-7 cells more strongly than chloroform and ethyl acetate extracts.

MCF-7 cells morphology showed the difference after $48 \mathrm{~h}$ of induction of extracts and positivecamptothecin (Figure 4). In the negative control DMSO 0.25\%, the cells grow into clusters, the cell morphology expands and adheres to the bottom of the feeding well. In the ethanol extraction sample, the cell membrane has a resolving phenomenon but obviously without affecting the cell development and clusters. In contrast to this, in the positive control and especially the extract from n-hexane, chloroform, and ethyl acetate, the cluster shrinkage and spread were significantly reduced, the cells were fragmented with cell membranes almost entirely resolved.

Table 3. The percentage of inhibited MCF-7 cell (\%) at concentration $100 \mu \mathrm{g} \cdot \mathrm{ml}^{-1}$ and $\mathrm{IC}_{50}$ of four extracts and camptothecin as the positive control

\begin{tabular}{|c|c|c|}
\hline Extracts and Positive control & Percentage of inhibition (\%) & IC $_{\mathbf{5 0}}\left(\boldsymbol{\mu g} \mathbf{~ m l}^{\mathbf{1}}\right)$ \\
\hline Camptothecin & $65.14^{\mathrm{b}} \pm 3.26$ & $0.005^{\mathrm{d}} \pm 0.001$ \\
\hline n-Hexane & $\mathbf{7 3 . 5 4 ^ { \mathrm { ab } } \pm \mathbf { 1 . 9 6 }}$ & $\mathbf{3 8 . 1 5 ^ { \mathrm { c } } \pm \mathbf { 1 . 5 8 }}$ \\
\hline Chloroform & $75.77^{\mathrm{a}} \pm 2.39$ & $65.76^{\mathrm{b}} \pm 3.67$ \\
\hline Ethyl acetate & $64.83^{\mathrm{b}} \pm 0.45$ & $77.73^{\mathrm{a}} \pm 2.12$ \\
\hline Ethanol & $3.81^{\mathrm{c}} \pm 9.32$ & - \\
\hline
\end{tabular}

The results are compared in each row, each different letter (a, b, c, etc.) is corresponding to each mean showing a statistical difference with $\mathrm{p}<0.05$. (-): Not detected 


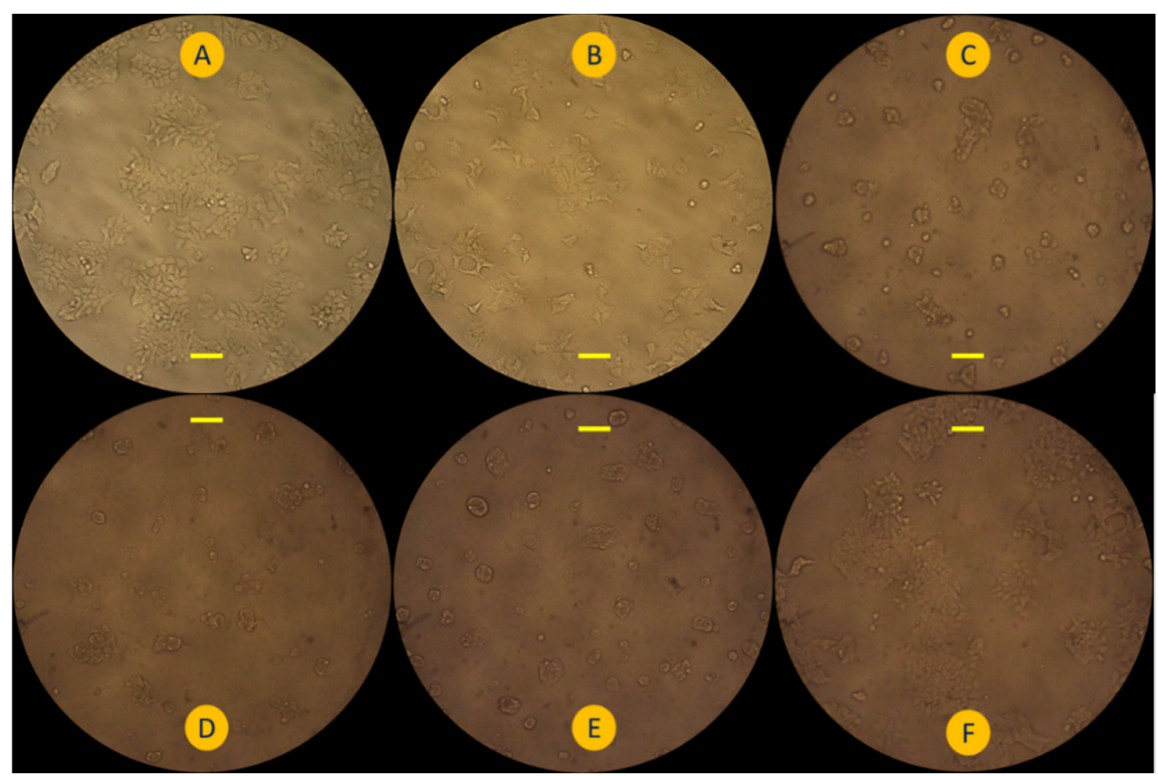

Figure 4. MCF-7 cell morphology after $48 \mathrm{~h}$ of induction with $0.25 \%$ DMSO (A), Camptothecin (B), nHexane (C), Chloroform (D), Ethyl acetate (E), and Ethanol (F) extracts. (Bar: $30 \mu \mathrm{m}$ )

Studies of the secondary metabolites of Marchantia polymorpha have shown that the bisbibenzyl group has excellent potential in inhibiting the growth of some cancer cell lines (Asakawa et al., 2000; Asakawa et al., 2013; Asakawa and Ludwiczuk, 2017). For example, Huang et al. reported that marchantin A induced the inhibition of MCF-7 cell growth via apoptosis through a caspase-dependent pathway (Huang et al., 2010). Asakawa $e$ t al. found that other bisbibenzyl marchantin C, D, and bisbibenzyl derivatives also had cytotoxicity on the KB and P-388 cell lines (Asakawa et al., 2013). In liverwort species, sesqui- and di-terpenoid compounds also contribute to the toxic activity on some cancer cell lines (Asakawa et al., 2013). Diethyl ether extract of

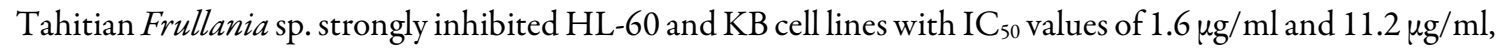
respectively (Asakawa et al., 2013). The sesquiterpene lactones such as costunolide and tulipinolide, presenting as the significant components in diethyl ether extract, have been reported to have intense inhibitory activity on these two cell lines (Asakawa., 1995; Komala et al., 2011; Asakawa et al., 2013). In M. polymorpha, typical sesquiterpene compounds include ent-9-oxo- $\alpha$-chamigrene, ent-thujopsan-7 $\beta$-ol, ent- $\alpha$-cyperone... (Asakawa $e t$ al., 1990).

Here, the results on the MCF-7 cell line show that n-hexane fraction, mainly weak polar compounds, might contain several bioactive that inhibit this cell line.

\section{Preliminary survey of secondary metabolites}

The qualitative results in Table 5 show that Marchantia polymorpha in vitro generally contains groups of phenolic compounds, quinones, coumarins, flavonoids, steroids, glycoside derivatives, and lactone ring compounds, and all these groups are present in chloroform and ethyl acetate extracts. Besides, the negative Cyanidin test showed that flavonoids include flavones, flavonols, chalcones, and aurons only. According to Markham and Porter, in M. polymorpha liverwort, luteolin and apigenin are the two main flavone flavonoids, besides their glycoside derivatives (Markham and Porter, 1974). In addition, the formation of these compounds is due to the activity of the enzyme chalcone synthase found in the M. polymorpha gametophyte tissue (Fischer et al., 1995). Therefore, products on the synthesis pathway would have the presence of chalcone, aurone, and naringenin (Asakawa, 1995; Fischer et al., 1995). 
Identified bioactive compounds found liverwort species, particularly in Marchantia polymorpha L. are mono-, sesqui-, di-terpenes, steroids, phenanthrenes, aromatic (bibenzyl or bisbibenzyl), flavonoids and its glycoside derivatives (Asakawa et al., 1990; Asakawa et al., 2013; Tanaka et al., 2016). Most of these compounds exist in the oil bodies of $M$. polymorpha and have non-polar to medium polarity (Asakawa et al., 2013; Tanaka et al., 2016), respectively, in the current study as n-hexane, chloroform, and ethyl acetate fraction.

Table 4. Result of preliminary qualitative analysis of secondary metabolite groups of four extracts of cultured Marchantia polymorpha

\begin{tabular}{|c|c|c|c|c|c|}
\hline Compounds & Reagents & I-Hex & I-Chlo & I-EAc & I-Eth \\
\hline Phenol & $\mathrm{FeCl}_{3}$ & + & + & + & - \\
\hline Quinone, coumarine & $\mathrm{KOH} 5 \%$ & + & + & ++ & - \\
\hline Tanin & Saline gelatin & - & - & - & - \\
\hline Alkaloid & Wagner & - & - & - & - \\
\hline \multirow{3}{*}{ Flavonoid } & $\mathrm{H}_{2} \mathrm{SO}_{4}$ & - & + & + & + \\
\hline & $\mathrm{NaOH} 1 \%$ & - & + & + & - \\
\cline { 2 - 6 } & Lead acetate 10\% & - & + & + & - \\
\cline { 2 - 6 } & Cyanidin-Mg & - & - & - & - \\
\cline { 2 - 6 } & Cyanidin-Zn & - & - & - & - \\
\hline \multirow{2}{*}{ Terpenoid-Steroid } & Roseinhem & - & - & - & - \\
\hline & Salkowshi & + & + & + & - \\
\hline Saponin & Foaming & - & - & - & - \\
\hline Glycoside & Molisch & + & + & +++ & + \\
\hline Lactone ring compounds & Baljet & + & + & ++ & - \\
\hline
\end{tabular}

Notes: $(+)$ presence, $(-)$ no. I-Hex, -Chlo, -EAc and -Eth correspond to n-hexane, chloroform, ethyl acetate, and ethanol extracts.

When comparing chloroform, ethyl acetate, and ethanol extract, that the number of compounds that contribute to the biological activity of chloroform and ethyl acetate fraction is more prominent than the ethanol fractions. The ethanol fraction had the highest extraction efficiency but mainly present flavonoids and glycoside compounds that made the biological activity of this fraction not stand out from the other remains. And other highly polar compounds in this fraction may not be involved in the biological activity examined. In some plant materials, ethanol is the right solvent to extract compounds that are highly polarized and have potent antioxidant activity (Abalaka et al., 2011; Jahan et al., 2014; Divya and Vijaya Anand., 2015; Amudha and Rani; 2016; Venkatesan et al., 2019). However, for in vitro M. polymorpha, solvents of lower polarity are more suitable than ethanol for extracting compounds that have positive results in these investigated activities.

The chloroform fraction has a weak polarization; the secondary compound groups in this segment have similarities with the ethyl acetate segment. However, this segment's antioxidant activity is lower than ethyl acetate but much more durable than that of $n$-hexane and chloroform segments. In addition, this segment is between $n$-hexane (non-polar) and ethyl acetate, so the chloroform segment also contains secondary groups similar to n-hexane. Therefore, in tyrosinase inhibitory assay and anti-proliferation activity on MCF-7 cell lines, the chloroform fraction is better than ethyl acetate although the biological activity is lower than $\mathrm{n}$-hexane.

The ethyl acetate fraction is the most pronounced presence of phenolic compounds and quinone, coumarin, glycoside derivatives when there was a product specificity during interaction with the reagent (expressed in numbers of $(+)$ signs more than other fractions). Besides of the above compounds, bisbibenzyls may be compounds that make ethyl acetate fractions have more prominent antioxidant activity than others.

Compared with the above fractions, the n-hexane lacks the flavonoid group. However, this fraction has many excellent activities such as antibacterial, tyrosinase inhibition, MCF-7 cell growth inhibition, and even $\alpha$-glucosidase inhibition (Tan et al., 2020). Therefore, the $\mathrm{n}$-hexane fraction is a potential target that needs further investigation both in terms of biological activity and natural compound. Also, the absence of too many 
groups of natural compounds (compared with ethyl acetate extract and chloroform) is a strong point of the nhexane extract, because this makes it easier to approach target compounds.

\section{Conclusions}

The in vitro Marchantia polymorpha is a potential source of materials with positive biological activities. Among four extracts, ethyl acetate had the best antioxidant activity in both reducing power test and DPPH scavenging models. All three n-hexane, chloroform, and ethyl acetate extracts have well antimicrobial activity and are relatively similar. The $\mathrm{n}$-hexane extract is prominent in tyrosinase inhibition activity and inhibiting the growth of MCF-7 cells. In addition, this fraction seems to be potent, and further biological activity, as well as new target compounds from this extract, should be further investigated.

\section{Authors' Contributions}

Conceptualization: Tran Quoc Tan and Quach Ngo Diem Phuong; Formal analysis: Tran Quoc Tan; Investigation: Tran Quoc Tan and Quach Ngo Diem Phuong; Methodology: Tran Quoc Tan, Phan Ngo Hoang and Quach Ngo Diem Phuong; Project administration: Quach Ngo Diem Phuong; Resources: Phan Ngo Hoang; Supervision: Quach Ngo Diem Phuong; Validation: Bui Lan Anh; Visualization: Bui Lan Anh; Writing - original draft: Tran Quoc Tan; Writing - review and editing: Bui Lan Anh and Quach Ngo Diem Phuong. All authors read and approved the final manuscript.

\section{Acknowledgements}

This research is funded by Vietnam National University Ho Chi Minh City (VNU-HCM) under grant number C2017-18-20. We also would like to thank MSc. Luong Thien Tam from the Department of Ecology and Evolutionary Biology, Faculty of Biology, University of Science, Vietnam National University-Ho Chi Minh City for identifying and authenticating the liverwort sample in nature.

\section{Conflict of Interests}

The authors declare that there are no conflicts of interest related to this article.

\section{References}

Abalaka ME, Mann A, Adeyemo SO (2011). Studies on in-vitro antioxidant and free radical scavenging potential and phytochemical screening of leaves of Ziziphus mauritiana L. and Ziziphus spinachristi L. compared with ascorbic acid. Journal of Medical Genetics and Genomics 3(2):28-34.

Amudha M, Rani S (2016). Evaluation of in vitro antioxidant potential of Cordia retusa. Indian Journal of Pharmaceutical Sciences $78(1): 80-86$.

Aneta S, Marina S, Jasmina G, Ana C, Milorad V, Boris P and Marko S (2011). Bio-activities of extracts from axenically farmed and naturally grow bryophytes. Journal of Medicinal Plants Research 5(4):565-571. https://academicjournals.org/journal/JMPR/article-full-text-pdf/A4D3C9F26089 
Asakawa Y (1995). Chemical constituents of the Bryophytes. In: Herz W, Kirby GW, Moore RE, Steglich W, Tamm CH (Eds.) Progress on the chemistry of organic natural products, Springer-Verlag, Vienna 65:1-618.

Asakawa Y, Ludwiczuk A (2013). Bryophytes: liverworts, mosses, and hornworts: extraction and isolation procedures. In: Roessner U, Dias D (Eds). Metabolomics Tools for Natural Product Discovery. Methods in Molecular Biology (Methods and Protocols). Humana Press, Totowa, NJ 1055:1-20. https://doi.org/10.1007/978-1-62703-577-4_I

Asakawa Y, Ludwiczuk A (2017). Chemical constituents of bryophytes: structures and biological activity. Journal of Natural Products 81:641-660. https://doi.org/10.1021/acs.jnatprod.6601046

Asakawa Y, Ludwiczuk A, Nagashima F (2013). Phytochemical and biological studies of bryophyte. Phytochemistry 91:52-80. https://doi.org/10.1016/j.phytochem.2012.04.012

Asakawa Y, Tori M, Masuya T, Frahm JP (1990). Ent-sesquiterpenoids and cyclic bis(bibenzyls) from the German liverwort Marchantia polymorpha L. Phytochemistry 29(5):1577-1584.

Asakawa Y, Toyota M, Tori M, Hashimoto T (2000). Chemical structures of macrocyclic bis-(bibenzyls) isolated from liverworts (Hepaticae). Journal of Spectroscopy 14(4):149-175. https://doi.org/10.1155/2000/570265

Balouiri M, Sadiki M, Ibnsouda SK (2016). Methods for in vitro evaluating antimicrobial activity: A review. Journal of Pharmaceutical Analysis 6(2):71-79. https://doi.org/10.1016/j.jpha.2015.11.005

Bowmann JL, Floyd SK, Sakakibara K (2007). Green genes-comparative genomics of the green branch of life. Cell 129:229-234. https://doi.org/10.1016/j.cell.2007.04.004

Chandra S, Chandra D, Barh A, Pandey R K, and Sharma IP (2016). Bryophytes: hoard of remedies, an ethno-medicinal review. Journal of Traditional and Complementary Medicine 7(1):94-98. https://doi.org/10.1016/j.jtcme.2016.01.007

Divya N, Vijaya Anand A (2015). In vitro antioxidant activity of ethanolic extract of Terminalia catappa leaves. Asian Journal of Pharmaceutical and Clinical Research 8(5):244-246.

Fischer S, Bottcher U, Reuber S, Anhalt S, Weissenbock G (1995). Chalcone synthase in the liverwort Marchantia polymorpha. Phytochemistry 39:1007. https://doi.org/10.1016/0031-9422(95)00097-Q

Gahtori D, Chaturvedi P (2011). Antifungal and antibacterial potential of methanol and chloroform extracts of Marchantia polymorpha L. Archives of Phytopathology and Plant Protection 44(8):726-731. https://doi.org/10.1080/03235408.2010.516083

Gawel-Beben K, Osika P, Asakawa Y, Antosiewicz B, Glowniak K, Ludwiczuk A (2019). Evaluation of anti-melanoma and tyrosinase inhibitory properties of marchantin A, natural macrocyclis bisbibenzyl isolated from Marchantia species. Phytochemistry Letters 31:192-195. https://doi.org/10.1016/j.phytol.2019.04.008

Ghasemi K, Ghasemi Y, Ebrahimzadeh MA (2009). Antioxidant activity, phenol and flavonoid contents of 13 citrus species peels and tissues. Pakistan Journal of Pharmaceutical Sciences 22(3):277-281. http://www.pjps.pk/wpcontent/uploads/pdfs/CD-PJPS-22-3-09/Paper-7.pdf

Gokbulut A, Satilmis B, Batcioglu K, Cetin B, Sarer E (2012). Antioxidant activity and luteolin content of Marchantia polymorpha L. Turkish Journal of Biology 36:381-386. https://doi.org/10.3906/biy-1106-15

Hanh NTM, Phung NKP, Phuong QND (2017). Studying on tyrosinase inhibition activity of some Vietnamese folk plants aims to use in skin-whitening cosmetics. American Journal of Plant Sciences 8:1319-1328. https://www.scirp.org/pdf/AJPS_2017052315321467.pdf

Hans DZ, Hans B, Theophil E (1991). Bryophytes, a source of biologically active, naturally occurring material. Angewandte Chemie International Edition in English 30:130-147. https://doi.org/10.1002/anie.199101301

Harborne JB (1984). Phytochemical methods; A guide to modern techniques of plant analysis. London: Chapman and Hall (2nd ed) pp 4-16.

Huang WJ, Wu CL, Lin CW, Chi LL, Chen PY, Chiu CJ, ... Chen CN (2010). Marchantin A, a cyclic bis (bibenzyl ether), isolated from the liverwort Marchantia emarginata subsp. tosana induces apoptosis in human MCF-7 breast cancer cells. Cancer Letters 291:108-119. https://doi.org/10.1016/j.canlet.2009.10.006

Jahan N, Parvin MS, Das N, Islam MS, Islam ME (2014). Studies on the antioxidant activity of ethanol extract and its fractions from Pterygota alata leaves. Journal of Acute Medicine 4(3):103-108. https://doi.org/10.1016/j.jacme.2014.05.001 
Jayaveera KN, Yoganandham RK, Govindarajula Y, Kumanan R (2010) Phytochemical screenings, antibacterial activity and physical chemical constants of ethanolic extract of Euphorbia thymifolia. International Journal of Pharmacy and Pharmaceutical Sciences 2(3):81-82. https://innovareacademics.in/journal/ijpps/Vol2Issue3/579.pdf

Komala I, Ito T, Yagi Y, Nagashima F, Asakawa Y (2011). Cytotoxic bibenzyls, germacrane- and pinguisane- type sesquiterpenoids from the Indonesian, Tahitian and Japanese liverworts. Natural Product Communications 6(3):303309.

Manmohan S, Arindam P, Hemendra PS (2014). Synthesis and reducing power assay of methyl semicarbazone derivates. Journal of Saudi Chemical Society 18(2):121-127. https://doi.org/10.1016/j.jscs.2011.06.004

Markham KR, Porter IJ (1974). Flavonoids of liverwort Marchantia polymorpha. Phytochemistry 13:1937-1942. https://doi.org/10.1016/0031-9422(74)85120-4.

My-Nuong TN, Thuy-Duong HH (2016). Selective cytotoxicity of a Vietnamese traditional formula, Nam Dia Long, against MCF-7 cells by synergistic effects. BMC Complementary and Alternative Medicine 16:220-230. https://doi.org/10.1186/s12906-016-1212-z

Nada C, Katarina S, Teodora J, Dejan P, Gordana Z, Svettana (2016). Optimization of polyphenols extraction from dried chokeberry using maceration as traditional technique. Food Chemistry 194:135-142. bttps://doi.org/10.1016/j.foodchem.2015.08.008

Remya K and Murugan K (2013). Polyphenols from Marchantia polymorpha L. a bryophyte: a potential source as antioxidant. World Journal of Pharmacy and Pharmaceutical Sciences 2(6):5182-5198. https://www.wjpps.com/Wjpps_controller/abstract_id/558

Sabovljevic MS, Vujicic M, Wang X, Garraffo HM, Bewley CA and Sabovljevic A (2017). Production of the macrocyclic bisbibenzyls in axenically farmed and wild liverwort Marchantia polymorpha L. subsp. ruderalis Bisch. et Boisselier. Plant Biosystems - An International Journal Dealing with all Aspects of Plant Biology 151 (3):414-418. https://doi.org/10.1080/11263504.2016.1179692

Shimamura M (2015). Marchantia polymorpha: taxonomy, phylogeny and morphology of a model system. Plant and Cell Physiology 57(2):230-256. https://doi.org/10.1093/pcp/pcv192

Singh M, Singh S, Nath V, Sahu V, Singh RAK (2011). Antibacterial activity of some bryophytes used traditionally for the treatment of burn infections. Pharmaceutical Biology 49(5):526-530. https://doi.org/10.3109/13880209.2010.523007

Tan TQ, Hoang PN, Vy LN, Anh BL, Nhut DT, Phuong QND (2020). Improving in vitro biomass and evaluating $\alpha$-glucosidase inhibition activity of liverwort Marchantia polymorpha L. Asian Journal of Plant Sciences 19:133-145. http://dx.doi.org/10.3923/ajps.2020.133.145

Tanaka M, Esaki T, Kenmoku H, Koeduka T, Kiyoyama T, Masujima T, ... Matsui K (2016). Direct evidence of specific localization of sesquiterpenes and marchantin A in oil body cells of Marchantia polymorpha L. Phytochemistry 130:7784. https://doi.org/10.1016/j.phytochem.2016.06.008.

Venkatesan T, Choi YW, Kim YK (2019). Impact of different extraction solvents on phenolic content and antioxidant potential of Pinus densiflora bark extract. BioMed Research International 2910 (ID 3520675). https://doi.org/10.1155/2019/3520675

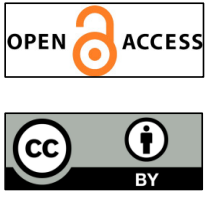

The journal offers free, immediate, and unrestricted access to peer-reviewed research and scholarly work. Users are allowed to read, download, copy, distribute, print, search, or link to the full texts of the articles, or use them for any other lawful purpose, without asking prior permission from the publisher or the author.

License - Articles published in Notulae Botanicae Horti Agrobotanici Cluj-Napoca are Open-Access, distributed under the terms and conditions of the Creative Commons Attribution (CC BY 4.0) License. (c) Articles by the authors; UASVM, Cluj-Napoca, Romania. The journal allows the author(s) to hold the copyright/to retain publishing rights without restriction. 